\section{- \\ Critical minerals bill introduced in US Senate}

www.energy.senate.gov
T he Critical Minerals Policy Act of 2013 (S. 1600) was introduced by a bipartisan group of US Senators on October 29, 2013. Critical materials are key components in a plethora of applications and industries from defense to clean energy to the medical sector to consumer electronics. While these materials often include rare-earth elements, they are considered critical not because they are scarce, but because for many applications there are not yet any viable substitutes.

Lisa Murkowski (R-Alaska), the Ranking Member of the US Senate Committee on Energy and Natural Resources, worked with Committee Chair Ron Wyden (D-Ore.) and Committee members Mark Udall (D-Colo.) and Dean Heller (R-Nev.) to craft the bill and introduce the legislation. Fourteen other senators have also signed on as co-sponsors. At press time, a Senate Energy and Natural Resources hearing was scheduled for January 28, 2014 to receive testimony on the Critical Minerals Policy Act of 2013.

The bipartisan support for this bill shows that many congressional leaders understand and share the concerns expressed by scientists and engineers in industry, academia, and government about the need for a steady supply of critical minerals. Important steps have already been made toward developing substitutes and improving critical materials recycling through the Critical Materials Institute, a Department of Energy (DOE) Energy Innovation Hub established in January 2013. But substitutes and recycling alone will not meet the demands for critical minerals, and a reliable supply of these materials is essential to the continuing growth of many high-tech industries in the United States.
According to the US Geological Survey's (USGS) report, "Mineral Commodity Summaries 2013," the United States is currently highly dependent on other countries for its minerals supplies. In 2012, the United States was $100 \%$ dependent on non-US sources for $17 \mathrm{~min}$ erals, over $75 \%$ dependent for 16 more minerals, and over $50 \%$ dependent for an additional eight minerals. While not all of these minerals are considered critical, these dependency levels give rise to concerns about stable critical mineral supplies and have led to efforts to establish a more active domestic program.

The Critical Minerals Policy Act of 2013 seeks to modernize the mineral policies in the United States and revitalize the domestic critical mineral supply chain. It directs the Secretary of the Interior to establish a method to determine which minerals are critical to the US economy and then to produce a list of these minerals. The National Academy of Sciences would be required to conduct an updated study concerning regulatory requirements.

The bill directs the Secretary of Energy to conduct research and development (R\&D) on nontraditional sources for rareearth elements and includes sections on a few specific elements including cobalt, lead, lithium, and thorium. Along with $\mathrm{R} \& \mathrm{D}$ on critical minerals recycling and efficiency, the bill promotes the development of alternative materials as well.

The bill aims to develop a domestic critical minerals supply chain that is environmentally responsible. It also aims to update the process of obtaining permits and to minimize delays as well as to strengthen international cooperation around critical minerals supplies.

The bill establishes annual analysis and forecasting by the USGS and the Energy Information Administration for critical domestic minerals supply, consumption, and recycling. Two more sections outline worker training for fields related to critical minerals and set guidelines for the Secretaries of State and Energy to promote international cooperation on critical minerals and their related technologies.

To pay for all of this, the bill reallocates $\$ 60$ million from the previously authorized Energy Independence and Security Act of 2007, to be spent over two fiscal years to fund the Critical Minerals Policy Act of 2013. 
This is not the first time in recent history that a critical minerals bill has been introduced in the Senate. The Critical Minerals and Materials Promotion Act of 2011 (S. 383) as well as the Critical Minerals Policy Act of 2011 (S. 1113) were both introduced in the 112 th session of Congress. In addition, multiple critical minerals or rare-earth bills were introduced in the House of Representatives during the last session of Congress. Despite the generally wide bipartisan support for establishing a domestic critical minerals program, none of these bills garnered the necessary support to become law.

The inability to pass legislation in an area with bipartisan support demonstrates that it has not been easy to develop a bill that can define critical but also allow that definition to evolve with advances in technology, fluctuations in mineral availability, and the ever-changing economic landscape. It is also difficult to draft a bill that strikes the right balance between protecting the environment and revamping the complex and time-consuming permitting process.

The Critical Minerals Policy Act of 2013 is the result of years of work and compromise by Senators and staffers on both sides of the aisle, and it attempts to set up a policy that will protect the environment while also creating a secure domestic critical minerals supply. While it remains to be seen if the Critical Minerals Policy Act of 2013 can garner the necessary support to become law, it is an important step forward to addressing US reliance on non-US sources for critical minerals supplies.

The full text of the bill can be found on the Senate Energy and Natural Resources website (www.energy.senate. gov), and in addition to the sponsors listed earlier, Senators Mike Enzi (RWyo.), Kay Hagan (D-N.C.), John Thune (R-S.D.), Chris Coons (D-Del.), John Hoeven (R-N.D.), Mary Landrieu (D-La.), Dan Coats (R-Ind.), Mark Begich (D-Alaska), Jim Risch (RIdaho), Amy Klobuchar (D-Minn.), Roy Blunt (R-Mo.), Al Franken (D-Minn.), Mike Crapo (R-Idaho), and Claire McCaskill (D-Mo.) have signed on to co-sponsor this legislation.

Jennifer A. Nekuda Malik
German Research Foundation establishes new Collaborative Research Centers www.dfg.de

$\mathbf{T}$ he Deutsche Forschungsgemeinschaft (DFG, German Research Foundation) has approved the establishment of nine new Collaborative Research Centers (CRCs), three of which have a materials research focus. The new CRCs will receive a total of $€ 64.4$ million for an initial period of three years and nine months and a $20 \%$ program allowance for indirect project costs. The Grants Committee also approved the extension of 23 existing $\mathrm{CRCs}$ for an additional funding period. As a result, the DFG will fund a total of 235 CRCs as of April 2014.

The CRC "Understanding of Oxide/Water Systems at the Molecular Scale: Structural Evolution, Interfaces and Dissolution" will be hosted by Humboldt University of Berlin, with spokesperson Prof. Dr. Christian Limberg. The Center will examine the elementary processes surrounding metal oxide-water interactions at all relevant length scales with a combination of chemical synthesis and modern experimental and theoretical methods. Metal oxides are used in both medical implants and in surface coatings and building materials. They generally form from an aqueous solution and often come into contact with water in their application areas. A detailed understanding of metal oxide-water interactions, which defines the oxide formation and dissolution processes, is therefore indispensable for the development of materials with the desired properties, as well as for ensuring their long-term stability. The other participating institutions are Free University of Berlin, Technical University of Berlin, University of Potsdam, German Federal Institute for Materials Research and Testing, Fritz-Haber-Institute of the Max Planck Society Berlin, and Helmholtz Center Berlin for Materials and Energy GmbH.

The transregional CRC "FunctionOriented Manufacturing Based on Characteristic Process Signatures," which will be spread across multiple research sites, will be hosted by the University of Bremen, with spokesperson Prof. Dr.-Ing. Ekkard Brinksmeier. It is possible to adjust measurements, forms, and surface geometries of components highly stressed in industrial production in a targeted manner. To date, this has hardly been possible for materials properties close to the surface, so-called fringe properties, such as residual stresses and rigidity. However, it is precisely these properties that are of decisive importance for the life span and the operating behavior of components, because stresses in the form of operating loads impact the component from the surface. It is therefore important to obtain a better understanding of the procedures involved in the manufacturing process that result in a change in materials properties. Participating institutions are RWTH Aachen University and Oklahoma State University, USA.

The transregional CRC "Tailored Nonlinear Photonics: From Fundamental Concepts to Functional Structures" will primarily concentrate on the physical principles and applications of non-linear light-matter interactions. One area of focus is the linking of promising concepts from quantum optics, coherent optics, and optoelectronics for the development of customized nonlinear photonic structures. A variety of applications in photonic information and quantum technology is planned for these new components. The host is the University of Paderborn, with spokesperson Prof. Dr. Artur Zrenner, and participating institution, Technical University of Dortmund. 